\title{
Stylistic Prescriptivism vs. Expert Practice ${ }^{1}$
}

\author{
Thomas N. Huckin \\ University of Utah
}

This article challenges a mumber of standard handbook nules by drawing on "tariety of empiriosl studies of cxpent writing. "17e rules in question involve the use of so-called expletives (existential "Ihere," the "it is" construction), nominalizations, and generic pronouns. In each case, the evidence gathered from corpus sampling and case studies shows that expert writers routinely ignore these handbook prescriptions. They do so, this article contends, because they know that language is a highly flexible and continually evolving instrument of communication and that these (proscribed) forms all have valid uses in certain contexts.

FOR CENTURIES PRESCRIPTIVE GRAMMARLANS have imposed rules of "correct" language usage on the general public. Known as the Handbook Tradition, these rules are taught to every schoolchild as if they are unerring indicators of a properly educated person. Current examples of such rules include "Use the active voice," "Be concise," "Avoid nouns created from verbs," "Unstring noun strings," and so on, all of which have become institutionalized in our handbooks, our writing coursés, our computerized style programs, and our editing practices. Often the discussion attached to these rules carries a moralistic tone, as if following the rules will not only make us better writers but will also make us better people.

A good example of this moralistic fervor can be found in the comments of a panel of usage celebrities about the perfectly innocuous word "hopefully," as used in sentences like "Hopefully, the war will soon be ended." This usage, according to the OED, dates back to the 14th century; and as Stanley Whitley shows in a masterful study published in American Speech (1983), it is a perfectly sensible usage no different than that of the word

1 This article is a version of the paper presented by Professor Huckin at the Conference of the Canadian Association of Teachers of Technical Writing in Ottawa, 1993. 
"surely" in a sentence like "Surely, she must have confused you with someone else." Yet when the I Harper Dictionar' of Contenporary Usage asked its socalled experts (pcople like Gcorge Plimpton, James J. Kilpatrick, and Andy Rooney) about the acceptability of "hopefully," their adverse reaction included comments like these: "Barbaric, illiterate, oflensive," "Sloppy and lazy," "Popular jargon at its most illiterate level," and, from Phyllis McGinley, "Hopefully' so used is an abomination and its adherents should be lynched" (p. 270).

The traditional basis for handbook rules has always been the subjective opinions of "authoritative people," people like Jonathan Swift, George Orwell, and E.B. White who have mastered a certain literary style and think that everyone should do likewise. This tradition is being carried on today by celebrity journalists like Edwin Newman and William Safire, and by panels of usage experts employed by dictionary publishers, as illustrated above. Working in parallel with this opinion industry, the education establishment has held up its end of the bargairi by subjecting generation after generation of students to the same body of conventional wisdom. And the computer software industry is keeping pace by incorporating traditional prescriptions into its style editing programs. Thus, it is no surprise that so many of our students and colleagues harbor notions of absolute correctness when it comes to language usage. I encounter this attitude everywhere I go: in my technical writing classes at the university in industry courses, and even in phone calls I occasionally get from anonymous citizens. Many people think there is only one correct way to use language, that it applies in all situations and contexts, and that as a writing teacher l must know what it is. When I bepin torespend to their queries by saying," "Well, it depends on . . , "Hey lhink l'm just being coy.

But, of course, I'm not. As a rhetorician and linguist, I know that language is not fixed and immutable, but rather is designed to be used according to the particular circumstances of a situation. Indeed, good writers know that they have to adapt their writing to the needs of the audience, to the exigency of the situation, and to their purposes as writers. The watchword should be "effectiveness," not "correctness." Professional writers may need no convincing on this score, but our students and colleagues often do. And I think the best way to convince them-in the face of years of indoctrination-is to present them with empirical evidence and reasoned analysis. In particular, we want to answer the question, "how do expert writers actually use language?" Expert writers are not necessarily expert analysts of writing, 
. : i i so merely soliciting their opinions (as l've just noted) may not tell us much. We want to know not what they say but what they actually do.

Unfortumately, empirical studies of expert writing vis-a-vis handbook rules are hard to find. l've been teaching a course on this subject for the past six ycars, so I've made it a point to look for good empirical studies in this area; yet I've found only a handful that are of any use. Indeed, I think it says something about the theoretical preoccupations of mainstream linguistics that there are so few empirical studies of a topic that has been in the public consciousness since at least the time of Jonathan Swift and Benjamin Franklin. But the studies that do exist are worth our attention, I think, because they underscore the fact that good writing is always rhetorical, always sensitive to its context and purpose, and always tactical and strategic.

The purpose of this article is to discuss some of these studies and to encourage readers to use them in their own teaching and advising. I will focus especially on those that are of most direct relevance to technical writing-studies that concen stylistic features common to technical writing and that examine the writing practices of technical professionals. These studies are corpus-based frequency data, and they document expert behaviour in an actual "real-world" setting, not in a laboratory or classroom. ${ }^{2}$

\section{Existential "There"}

Let's begin with the various handbook proscriptions against expletive sentences. Expletive sentences are those that begin with so-called "empty words" like "it" and "Here," such as "It's possible that our client simply for-

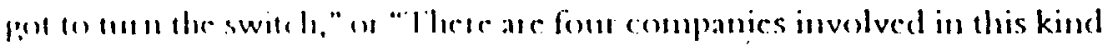
of eesearch." Ihe sell appointed puardians of stylistic purity have long railed against expletive sentences, and the tradition continues alive and well today. Almost every technical writing handbook on the market has something bad to say about these kinds of sentences. Here are some examples from two recently published books: "Avoid the following expletives: 'there is', 'are,' etc.; 'it is,' "was'" (Gerson and Gerson, 1992, p. 35); "Eliminate expletives"; and "Authors begin sentences with expletives or 'crutch words' (like 'there'

2 A number of studies can be found in the literature that cxamincs stylistic prescriptions from a reading-process perspective. In these studics, typically, groups of students are asked to read isolated texts, phases, or sentences and are then tested for comprehension. Since these studies do not include full rhetorical contexts, I feel they lack ccological validity and have thu's excluded them from consideration. 
and 'it') because they won't expend the effort necessary to find the true subject of the sentence and place that subject first in the sentence" (Mancuso, 1992, p. 157). The underlying assumption in all of these cases is that a difference in form entails no difference in meaning. For example, Felker et al's Gtidelines for Document Designers, published by the American Institutes for Research, assumes that these two sentences have the same meaning:

a. There are three people who can sign this application.

b. Three people can sign this application (1981, p. 57).

If they did have the same meaning, then yes, it would make sense to opt for the shorter version. But I think they do mot have guite lle same meaning:

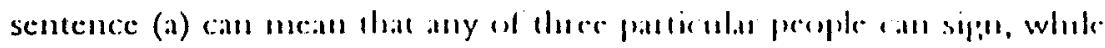
sentence (b) can mean that the application may have thee signatures. In ignoring these subtle differences of meaning, those who devise such guidelines are reducing the expressive power of the language.

Several years ago I decided to test this particular prescription with a little empirical research. Helped by a technical writer/editor from the $\mathrm{Na}$ tional Software Engineering Institute (SEI) in Pittsburgh (Linda Hutz Pesante), I compiled a sample of 100,000 words from 29 publications including The Merck Manual, The Bell System Technical Journal, National Geographic, Macivorld, Guidelines for Document Designers, and The Encyclopaedia Britamnica. My research partner and I then went through the corpus, identifying 169 instances of existential "there," or an average of 1 per 592 words. This may not seem like a very high frequency, but actually it is: a $1: 592$ ratio makes it one of the 50 most frequently used words in the corpus. More extensive studies, like the million word Brown Corpus, find the existential "there" occurring once every 438 words, suggesting that it's the forty-first most common word in the English language. Since our corpus was made up of writing that we believed most people would accept as "good" writing, the heavy use of existential "there" in these publications constituted prima facic evidence; we felt that it was serving a useful and respectable purpose. Just to make sure, though, we decided to do a double-blind confirmation study with professional technical editors. We randomly selected one "there" sentence from each of our 29 sources and typed it on a sheet of paper along with enough surrounding context (usually a paragraph) to enable a reader to make sense of it. We then found three writers/editors at the SEI and asked them each, independently, to look at the 29 sentences and see if "there are any sentences that are not well written, that you would want to revise if you had the time." These experts had 41 years of combined experience as professional editors 
and 22 years of combined experience as writing teachers; they were all accustomed to reading manuscripts closely and critically, and indeed they found fault with a number of linguistic features in these texts, including punctuation, syntactic constructions, and word choice. But they found virtually nothing wrong with any of the "there's." There were 35 instances of "there" in the 29 paragraphs, and only one of the editors objected to any of them. (This one editor found fault with two of them; interestingly, she was the only one of the three who was aware of the handbook rule.)

When we did a rhetorical-linguistic analysis of each of the 169 "there's" in we finll corpus, we had no trouble accounting for their use. Fxistential

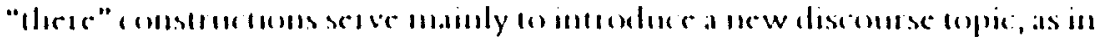
lhe following example:

Most professional dietitians favour a program of gradual, moderate changes in eating habits, often recommending 'grazing,' or eating many small meals throughout the day. It can take a year 'to change people's way of thinking and behaving in regard to eating,' says Sherry Siegel, founder of a Chicago weight-consulting firm. There are also those who proffer unorthodox advice, like $\mathrm{Oz}$ Garcia, a successful, self-taught New York City nutritionist who decides what clients should eat after he has analyzed their hair. 'I was a walking penny," says Amy Greene, 54, a makeup consultant at the chic Henri Bendel store. Garcia found that her hair had a high copper content; he decided that she must stop drinking her usual 16 cups of tea a day (Time, January 12, 1987, p. 64; emphasis added).

The "there" sentence in the middle of this paragraph signals the introduction of a new discourse topic ( $\mathrm{O} z$ Garcia, an morthodox mutritionist). Indeed, it is difficult to think of another way of topicalizing $\mathrm{Oz}$ Garcia without using a "there" sentence. In our corpus, $94 \%$ of the "there" sentences served this purpose, with the remaining $6 \%$ being used to summarize or reiterate some point. We found case after case like this, especially in reference books and technical journals (where there tends to be a steady procession of new discourse topics).

\section{Anticipatory "It"}

Another expletive worth keeping is the anticipatory "it," as in the 
sentence "It is important to read the directions carefully before turning on the machine." As Lilita Rodman explains in a 1991 article in the Journal of Technical Writing and Communication, "it" serves a number of important functions. Rodman cxamined eight journal articles and four textbook chapters, totalling 70,000 words, from the ficlds of mineralogy, chemical enginecring, physics, civil engincering, and geology. Presumably, these articles and chapters were written by reasonably competent writers, or, if not, were at least edited by reasonably competent editors. Rodman counted 205 "it"clauses in her sample, suggesting that these writers and editors found it a useful sentence type. Far from being a "meaningless" construction, Rodman found that the anticipatory "it enabled writers to make evaluative information, or to summarize or preview main points.

The findings of Rodman's empirical research are supported by an analytic study by Gerald Delahunty. Delahunty surveyed 50 handbook and composition textbooks for rule statements about the expletive "it" and then compared these statements to the many instances of "it" sentences that he came across in his daily reading. He found that the handbooks generally treat "it is" as an empty construction and recommend getting rid of it. For example, instead of saying "It is apparent that we can't agree," the Prentice-Hall handbook recommends, "Apparently we can't agree." But Delahunty notes that in many such cases, changing the form of the sentence means changing its meaning. Sometimes the change of meaning is quite subtle, as in the case just cited; at other times, it can be quite drastic. For example, the Harbrace College I landbook (10th edition, 1986, p. 236) recommends changing sentence (a) into sentence (b):

a. It secms to me that a woman can be as guilty of sexism as a man.

b. $\Lambda$ woman can be as guilty of sexism as a man.

But clearly, the second version lacks the modal qualification of the first, which may be very important in a given context. Harbrace (p. 242) also recommends changing sentence $(c)$ into sentence $(d)$ :

c. It is easy to learn to type.

d. Learning to type is easy.

But one can easily imagine cases where such a transposition would only create awkwardness in end-weight and sentence rhythm. Consider, for example, this sentence that leads off the concluding paragraph of a long article:

e. It should be evident from this account that substantial technical problems remain to be solved before a total artificial heart can be routinely utilized in human patients. (Jarvik, 1981, p. 80). 
Few professional writers, I think would prefer this non-expletive version:

f. That substantial technical problems remain to be solved before a total artificial heart can be routincly utilized in human patients should be cuident from this accoume.

As has been observed by many functional grammarians over the past fifty ycars (c.g., Jesperson, 1964; Quirk et al., 1972; Williams, 1994), speakers of English usually find it easier to deal with long, complex noun phrases and subordinate clauses at the ends of sentences than at the beginnings of sentences. Anticipatory "it" (or what Jesperson calls "preparatory "it") is one of the primary mechanisms in the English language for accomplishing this purpose.

\section{Nominalizations}

Another common set of handbook rules relates to the use of nominals. Virtually cvery handbook on the market rails against anything having to do with nominals-nominalizations, noun compounds, periphrastic expressions, and so on. I believe this bias springs again from literary tastes, since literary style typically has a higher verb-to-noun ratio than does technical writing. Here are some examples of the kinds of handbook rules you find: "Avoid nouns created from verbs" (Felker et al., 1981); "Unstring noun strings" (Felker et al., 1981); "Eliminate expletives and nominals" (Mancuso, 1992); "Change nominalizations [back to verbs]" (Feinberg, 1989); and "Avoid nominalizations" (Eisenberg, 1992). Such rules ignore the fact that nominals are hasic on the lan!nape. Nonice, for example, how some of these very guide-

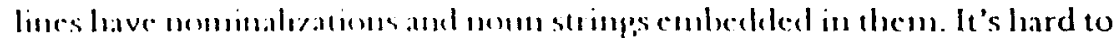
alk about momintizations without using the word "nominalization, "which is itself a nominalization, and it's hard to talk about noun strings without using the term "noun string" which is itself a noun string. Even identifying nominalizations can be a problem. To see this, consider the following list of nouns: amendment, refusal, criticism, talk, print, obstruction, beggar, and reminiscence. Which ones are nominalizations (i.e., nouns derived from verbs)? The answer is that the first four are nominalizations and the last four are not. These last four do, of course, have related verbs--print, obstruct, be, and reminisce-but they were all derived from the noun, not the other way around. (Perhaps all handbook writers should be required to demonstrate their ability to identify nominalizations before they're allowed to tell anyone to avoid them!) 
Anyway, let's grant that some people do sometimes use a noun-heavy style, and that such a style can be impersonal, abstract, wordy, and sometimes unclear as to who is doing what to whom. Indeed, the psycholinguistic research of E.B. Coleman in the 1960s found that, all other things being equal, a noun-heavy style is more difficult to process than a verb-heavy one. But is that sufficient justification for a handbook rule against nominalizations in general? After all, nominalizations do have the potential for many positive uses:

- They can help create cohesion between scontences, as in this example:

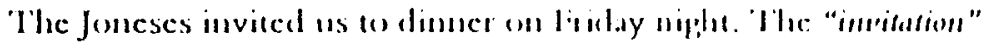
arrived by mail yesterday.

- They can be modified more easily than verbs.

- They can be used as modifiers of other nouns.

- There are usually more "slots" in a sentence for nouns, including nominalizations, than for verbs.

- By omitting reference to personal agents, nominalizations foster economy of expression.

- By omitting reference to personal agents, they create politeness through indirectness.

- They are "heavier" than other parts of speech and thus can add a touch of elegance, especially at the ends of sentences, as seen in this example from Walter Lippman: "This shows that the preservation and defense of freedom of opinion is not only a matter of adhering to abstract legal rights but also, and very urgently, a matter of organizing and arranging sufficient debate." Joseph Williams notes that a less noun-heavy version of this sentence would be less graceful: "This shows that if we want to preserve and defend free opinion, we must not only adhere to abstract legal rights but also, and very urgently, organize and arrange things so that we can debate issues sufficiently" (1994. p. 161).

- They can become lexicalized (e.g., treated as independent entries in a dictionary, not merely included as derived forms) and take on new meanings. For example, "organization" is not simply a nominal version of "organize," but rather a reified entity ("society," "association"). This explains why a sentence like "Our organization is pretty disorganized" is not a contradiction in terms.

- They often denote abstractions and, as Richard Ohmann has argued, 
"Some important kinds of thinking can be done only with the help of abstractions" (1979, p. 396). Ohmann's paper challenges the Strunk and White maxim, "Use definite, specific, concrete language" (1979, p. 21), by presenting numerous cases where abstract language captures a different, richer meaning.

- For all of the reasons just cited, nominalizations are commonly used in scientific and technical contexts and thus are seen as a stylistically appropriate feature in the scientific/technical linguistic "register."

In stmmary, it might be said that although the use of nominalizations may

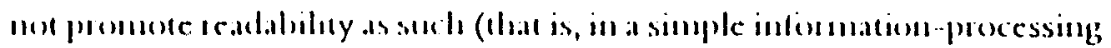
sense), it does make it casicr for writers to creatively express different kinds of meaning.

Empirical research from the professional workplace illustrates some of these points. In a series of experiments, Rosemary Hake and Joseph Wrlliams prepared two stylistically different versions of the same essays (one in a heavily nominal style, the other in a heavily verbal style) and had 73 typists type both versions (1981). They found that these typists typed the verbal style essays faster and more accurately than they did the nominal style essays. which supports Coleman's finding that the verbal style is cognitively easier to process. But when Hake and Williams had 118 composition instructors from high schools and colleges in Illinois and Georgia rate these essays on a variety of measures, they came up with a different sort of finding. Although these instructors routinely taught their students to use a verbal style, when it came to evaluating these essays they consistently favoured the nominal style. In fact, their preference for the nominal style was so strong that it seemed to colour their judgments about the essay's content. Essays written in a nominal style were judged to be higher in intellectual quality than the same essays written in verbal style. One teacher, for example, said that the nominal-style version displayed "an intelligent understanding of the problem;" when he later read the verbal-style version, he described it as "Flippant and without purpose other than criticism." And many other evaluators responded similarly. Thus, in the minds of these teachers-and, one would guess, in the minds of their students-simple readability is not the most highly valued aspect of style.

Hake and Williams bemoan these results, saying that a preference for the nominal style reflects a longstanding decline in standards due to mass education, insecurity, an ignorance of how to write any better, and poor 
teaching. This puts them, of course, in the company of Edwin Newman, William Safire, John Simon, and all the other gloom-and-doomers trying to "preserve the language" against the onslaught of the illiterate masses. But Hake and Williams's interpretation of these results depends on the assumption that the differences between these versions are merely a matter of stylistic variation and that style was completely scparate from content. I would argue that form and content are interrelated and that different linguistic forms carry different meanings. In some cases the differences may not entail differences in truth value, as traditional semantics puts it, but differences of a more subtle sort involving connotation, emphasis, tone, and other rhetorical factors. Like so many other prescriptivists, Hake and Wrlliams seem insensitive to this rhetorical dimension even when the evidence from 118 experienced professionals clearly points to it.

Similar findings, but with a more enlightened interpretation, can be found in an ethnographic study conducted by Robert L. Brown and Carl Herndl (1986). Brown and Herndl studied the writing practices of 34 middle managers and other professionals in two Fortune 500 corporations, one a computer and business-service company, the other an agricultural, commodities, and consumer goods company. Eight of these 34 professionals were identified unanimously by their managers and peers as the best writers in their unit. The other 26 were undistinguished. Brown and Herndl were interested in finding out why these writers used "superfluous nominalizations" despite being advised by writing teachers not to. (Superfluous nominalizations are periphrastic constructions like "perform an examination" instead of the simpler "examine.") They found that the so-called good writers used such constructions rather fiequently (mose than 6 times per lhousand words). and that the undistinguished writers used them even more frequently (an average of 13 times per thousand words), especially those employees who felt some anxiety about job security.

A traditional prescriptivist explanation for these results, as Brown and Herndl point out, would assume first, that the superfluous nominal is in fact a stylistic error and second, that these writers are therefore making mistakes, probably due to mediocre competence exacerbated by job stress. But such an account would not explain why even the best writers suffering from apparent job stress used many superfluous nominals. Indeed, one could point to the other, more famous writers, and ask why they use superfluous nominals from time to time, as E.B. White does in this sentence: "I think it might be useful to stop viewing fences for a moment and take a close look at Esquire's 
way of doing business" (1976, p. 657). Why would E.B. White use a phrase like "take a close look at" instead of a more concise "look closely at," if there were no difference in meaning?

Brown and Herndl therefore looked more decply and noticed that whenever these employees wrote for upper management their use of superfluous nominals would increase, and whenever they wrote down the hierarchy their use of superfluous nominals would decrease. They attributed this pattern not to incompetence or "dysfluency," but to cultural factors emanating from the corporate environment. The use of periphrastic nominals enabled these writers to be less assertive, more tentative in their tone toward upper management: "make a recommendation" is not as direct as "recommend." In adopting this more cautious tone, these employees were not only showing more respect to their superiors but also displaying their loyalty to the company through their identification with the corporate style. In short, whether we like the result or not, these employees' stylistic choices appear to be deliberate, not inadvertent. Brown and Herndl conclude: "In our view of things, ostensible core conventions, or 'good writing,' go the way of standard dialects in sociolinguistics: the conventions shift and change, to be replaced by other conventions, all dictated by contextual criteria. What is 'good' is what meets the complex needs of the language culture" (p. 23).

Another empirical study relevant to the use of nominalizations is that of John Kosteinick, who examined a 90-page manual of model suggestion letters written by auditors in a Big Eight accounting firm (1981). Hagge and Kostelnick found these letters filled with nominalizations, expletives, passives, and hedpes, stylistic features which are all stipmatized in business writing

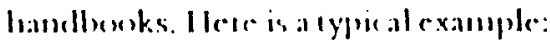

Based on our limited view, it appears that internal audit could contribute significantly to the Corporation through increased involvement in user testing and reviews of specific applications before implementation and on a post-implementation basis. At a minimum, internal audit should be notified of all program changes and major scheduling/processing changes. Additionally, internal audit should participate in the development and testing of new systems and major changes whenever possible. Internal audit may also be of assistance in preparation and planning for the new facility (p. 316).

One is tempted to dismiss such prose as "typical bureaucratese." But Hagge 
and Kostelnick decided to explore why auditors write this way and, more importantly, why they apparently want to write this way. Working as participant-observers, they found that the auditors they observed were often in tenuous situations when they wrote reports to clients. For legal, ethical, and professional reasons, these auditors were obliged to convey critical appraisals in their reports; yet they didn't want to offend clients with harsh accusations, and they seldom had sufficient information to make unqualified accusations anyway. In short, these auditors dealt with a great deal of uncertainty and therefore felt they had to be very diplomatic in their communications with clients.

By doing a linguistic analysis of ilse model lecteas onntined in the Simple: Book, Hagge and Kostelnick found that the writers of these letters relied heavily on politeness strategies as detailed in Brown and Levinson's classic book on the subject (1987). In particular, they found that these writers depended on expressions of what Brown and Levinson call "negative politeness," or respect for the reader's privacy and self-esteem. Negative politeness is characterized by "self-effacement, formality, and restraint" (p. 70). Statements that might be construed as threatening to the self-image of a reader can be mitigated with hedges, with impersonalizing mechanisms (such as nominalizations and agentless passives), and with other softening devices. Hagge and Kostelnick state that "the use of such negative politeness strategies, along with their concomitant linguistic realizations in the surface grammar of their texts, then, represents a rational response by the accounting firm's auditors to situational pressures and institutional norms of the accounting profession" (p. 321).

\section{Generic pronouns}

A particularly confusing issue of linguistic usage these days concerns the problem of what pronoun to use when referring to a singular, genderneutral anteredent. For example. in a setting involving both male and female students, a sentence like (a) would be considered sexist by many people today because the generic pronoun his is identical in form to the standard male pronoun.

a. Every student has his own access code.

(Experimental evidence that this linguistic conflation has significant biasing effects on comprehension can be found in MacKay, 1980.) But is there a good alternative to this traditional usage? Consensus opinion among today's 
handbooks (e.g., Eisenberg, Gerson and Gerson, Houp and Pearsall, Markel) seems to be that there are basically three ways around the problem (in descending order of preference): (1) pluralizing the referent, (2) rewording the sentence to avoid any use of a pronoun, or (3) using "he or she" (or some variant thereof). Thus, sentence (a) could be rewritten as:

b. All students have their own access code.

c. Every student has a personal access code.

d. Every student has his or her own access code.

This is reasonable advice, but in each case something is lost. Pluralizing the

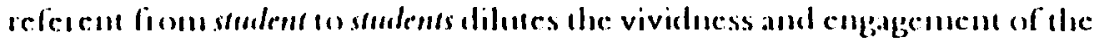
singular. Rewording the sentence so as to eliminate the per sonal pronoun, as in (c), has an even more pallid result. Using his or her is cumbersome both semantically and phonologically.

Recognizing these problems, Miriam Watkins Meyers reviewed the sociolinguistics literature (and her own linguistic experience) and noticed that for many educated people the singular generic pronoun of choice seemed not to be he but they, as in "Every student has their own access code." She decided to test her impressions empirically. She analyzed carefully revised essays written by 392 college juniors and seniors enrolled in an upper- and graduate-level Minnesota university, ranging in age from 22 to 64 years, with an average of 34 . The essays all addressed the topic, "What is an educated person?", which encouraged the writers to talk about a singular, gender-neutral topic (an educated person) and, in so doing, to deal with the pronoun problem (1990).

Meyers found that $48 \%$ of the 392 writers avoided the problem by pluralizing the subject, by using no pronouns at all, 'or by using some other technique. Of the 52\% who did confront the problem, about one-third took an inconsistent approach employing a variety of methods. The remaining two-thirds (138 writers) consistently favoured one particular pronominal form, with the generic "le" and the singular generic "they" favoured about equally ( $34 \%$ and $32 \%$, respectively), and "he or she" prevalent as well (22\%).

Meyers concludes from her study that "singular 'they' is well-established in the public writing of adult Americans" (p. 234). Although this conclusion seems a little overstated given the relatively small and localized pool of research subjects used, it does seem to be a fact that singular "they" is quite common even among highly educated speakers around the country. To support her point, Meyers cites examples from Stephen Jay Gould ("Every naturalist has their favourite adaptations"), William Sloane Coffin, Jr. ("If anyone 
thinks I'm controversial, it shows how far removed they are from controversy"), and many others, including U.S. Senators, judges, university presidents, and linguists. Elizabeth Sklar in a 1988 article in College Composition and Communication provides further support through linguistic analysis and historical evidence (from Shakespeare, Dickens, Arnold, Swift, etc.). Even the Ontario Legislature recently (December 2, 1993) legalized the use of singular "they" for the writing of provincial statutes.

The point I wish to make here is not that the singular "they" is necessarily the best way to deal with the generic pronoun problem but simply that it should be considered a reasonable candidate for such a role. The fact that virtually no handbook on the market even mentions it as a possibility is an indication of how traditional and hidebound these handbooks are. ${ }^{3}$ If highly competent users of the language use a certain linguistic form with some frequency, then prescriptive grammarians should take this into account and recognize that there must be some legitimacy to such usage.

\section{Conclusion}

The topics discussed here-existential "there," anticipatory "it," nominalizations, and generic pronouns-represent only a few of those commonly treated in the style sections of technical writing and other professional writing handbooks. Unfortunately, however, they also largely constitute the extent of the reseafeh in this area. Most of the empirical studies of standard prescriptions that I am aware of (and I have surveyed the sociolinguistics, specch communication, technical writing, and composition litenture for many years) concen these finte topies. Not even the most talked about stylistic copic of all-use of the passive voice has becon sulyjected to the kind of careful empirical scrutiny that is found in the studies mentioned above. There is certainly a need for more research of other topics (e.g., noun compounding, hedges, sentence length, conciseness, and particular words and expressions).

But perhaps even these few studies are having a salutary, consciousnessraising effect, beyond their immediate concerns, on prescription in general. I've noticed that many recently published handbooks display a somewhat

3 Zuber and Reed (1993) note that during the mid-1980s a few leading handbooks briefly softened their stand against the singular "they," but then regressed in the 1990 s to the traditional, unqualificd proscription. 
changed attitude about stylistic rules. Instead of striking the traditional absolutist tone, they are more temperate in their language. For example, instead of saying "Unstring nom strings" (Felker, 1981), they may say that "writers should hold their strings to three words or fewer and not use more than one per paragraph" (Houp and Pearsall, 1992). Instead of saying "Use the active voice" (Strunk and White, 1979), they now say something like "Use the active voice to emphasize the agent, passive voice to emphasize the object" (Eisenberg, 1992). Furthermore, in their discussions of style, these more recent publications display an unusual sensitivity to the functionality and adaptive nature of language. This is good news, because the use of language always represents a struggle between stability and change. Language is not a static, fixed entity but is always somewhat flexible and plastic so as to serve diverse human needs; and "correctness" should always be judged according to the audience, the purpose, and the situation.

Specialists in technical communication presume to have little personal need for guidelines or other advice on how to write. But they often perform roles where they are expected to be language experts and give advice toothers. For example, they may be asked to put together a set of company style standards. Or they may be asked to teach an in-house course on how to write memos or business letters. Very often they serve as the unofficial (and perhaps involuntary) company linguist, answering questions about matters of style, grammar, punctuation, and so on. In any of these situations, they will almost certainly have to deal with a longstanding cultural mindsct about stylistic propriety. In situations like these, it may help to know that there is some

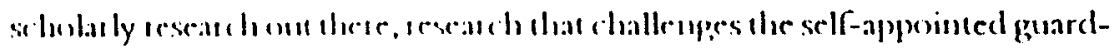

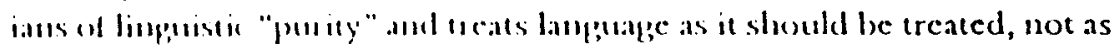
some inmmutable possession of an enlightened class of people but rather as a living instrument of human expression. I hope this article will help serve that purpose.

\section{References}

Brown, R., \& Herndl, C. (1986). An ethnographic study of corporate writing: job status as reflected in written text. In B. Couture (Ed.), Functional approaches to writing: research perspectives (11-28). Norwood, NJ: Ablex. 
Brown, P., \& Levinson, S. (1987). Politeness: Some universals in language usage. Cambridge: Cambridge University Press. (Originally published in 1978 as part of Esther N. Goody (Ed.), Questions and politeness.

Cambridge: Cambridge University Press.)

Coleman, E.B. (1964). The comprehensibility of several grammatical transformations. Joumal of Applied Psychology, 48, 186-190.

Coleman, E.B. (1962). Improving comprehensibility by shortening sentences. Journal of Applied Psychology, 46, 131-134.

Delahunty, G. (1991). The powerful pleonasm: A defense of expletive "it is." Written Communication, 8(2), 213-239.

Feinberg, S. (1989). Technical writing. NY: Holt, Rinchart and Winston.

Hagge, J., \& Kostelnick, C. (1981). Style and its consequences: Do as I do, not as I say. College English, 43(5), 433-451.

Huckin, T., \& Pesante, L.H. (1988). Existential "there." Written Communication, 5(3), 368-391.

Jarvik, R.K. (1981). The total artificial heart. Scientific American, 244(1), 7491.

Jesperson, O. (1964). Essentials of english grammar. University, AL:

University of Alabama Press.

MacKay, D. (1980). Psychology, prescriptive grammar, and the pronoun problem.American Psychologist, 35(5), 444-449.

Meyers, M. (1990). Current generic pronoun usage: An empirical study. American Speech, 65(3), 228-237.

Morris, W. \& Morris, M. Eds. (1985). Harper dictionary of contemporary usage. NY: Harper and Row.

Ohmann, R. (1979). Use definite, specific, concrete language College English, 41 (4), 390-397.

Quirk, R., Greenbaum, S., Leech, G., \& Svartvik, J. (1972). A grammar of contemporary english. London: Longman.

Rodman, L. (1991). Anticipatory "it" in scientific discourse. Joumal of Technical Writing and Communication, 21 (1), 17-27. 
SkJar, E. (1988). The tribunal of use: Agreement in indefinite constructions. College Composition and Communication, 39(4), 410-422.

White, E.B. (1976). Letter to the editor of the Ellsworth (Maine) American-North Brooklyn, January 1, 1976. In Dorothy Lobrano Guth (Ed.), Letters of E.B. White (p. 657). New York: Harper and Row.

Whitely, M.S. (1983). "Hopefully": A shibboleth in the English adverb system.American Speech, 58(5), 126-149.

Williams, J. (1994). Style: "len lessons in clarity and grace. New York: I larper Collins.

Zuber, S., \& Reed, A.M. (1993). Generic "he" and singular "they." College English, 55(5), 515-530.

\section{Handbooks cited}

Eisenberg, A. (1992). Effective technical communication (2nd ed.). New York: McGraw-Hill.

Felker, D., Pickering, F., Charrow, V., Holland, V.M., \& Redish, J. (1981). Guidlines for document designers. Washington: American Institutes for Research.

Gerson, S.J., \& Gerson, S.M. (1992). Technical Writing: Process and Product. Englewood Cliffs, NJ: Prentice-Hall.

Hodges, J.C., Whitten, M.E., \& Webb, S.S. (1986). Harbrace college handbook (10th ed.). San Diego, CA: Harcourt Brace Jovanovich.

Houp, K., \& Pearsall, T. (1992). Reporting technical information (7th ed.). New York: Macmillan.

Mancuso, J.C. (1992). Technical editing. Englewood Cliffs, NJ: PrenticeHall.

Markel, M. (1992). Techmical writing (3rd ed.). New York: St. Martins.

Mathis, J.C. \& Stevenson, D. (1991). Designing technical reports. New York: Macmillan.

Strunk, W., \& White, E.B. (1979). The Elếments of style (3rd ed.). New York: Macmillan. 